\title{
Wen Ling \\ Exploration and Practice in Systems Engineering Management of Large Coal-based Integrated Energy Projects of Shenhua
}

\begin{abstract}
With an analysis of current development of China's coal industry, this paper, in the perspectives of concept innovation, technological innovation and management innovation, introduces the exploration and engineering practice by Shenhua Group in coordination with coal and the environment, co-development of coal and the associated resources as well as clean and efficient utilization of coal. Based on systems engineering of Shenhua's coal-based integrated energy projects, the paper also presents practice and experience in technological and management innovation.
\end{abstract}

Keywords: coal-based, integrated energy, systems engineering, exploration, practice

\section{Foreword}

Energy is vital for economic and social development. China has much less energy and resource reserves than the global average, with per capita share of coal equaling $67 \%$ of the global average, oil $5.4 \%$ and gas $7.5 \%$. Today, China is highly dependent on imported oil and gas, and it will be difficult to produce a large amount of new and renewable energies in the foreseeable future. China is under huge pressure in energy supply due to changes in the global geopolitical landscape, evermore intense competition over energy and resources and tightening environment constraints. Coal is the main energy source in China; thus its clean and efficient development and utilization is of great significance to national energy security. As a state-owned enterprise (SOE) under the Central Government, Shenhua Group actively fulfills its political, economic and social responsibilities and has long been committed to improving the coal-based integrated energy system.

Manuscript received February 15, 2015; accepted June 5, 2015

Wen Ling $(\bowtie)$

Shenhua Group Corporation Limited, Beijing 100011, China

Email: lingw@shenhua.cc

\section{Background}

2.1 Coal Revolution is essential to energy revolution

\subsubsection{Coal as the main source of energy}

China's scarcity of oil and gas and relative abundance of coal determines that coal's dominance in the energy mix will not change in the foreseeable future. In 2014, China consumed 4.26 billion TCE of primary energy, among which $66 \%$ or 2.8 billion TCE was coal. Currently, only hydro power and solar thermal technologies are mature, while technologies for wind and solar power generation are still at the primary stage. It is estimated that coal consumption will account for $62 \%$ of the total primary energy consumption in 2020 (The General Office of the State Council, 2014), and 50\%-55\% of the overall energy consumption in 2030 (The Chinese Academy of Engineering, 2014).

\subsubsection{Serious negative impact on ecology}

At present, problems still persist such as unreasonable layout of China's coal industry, rudimentary development methods and negative impact on ecology. In China, coal mining produces about 8 billion cubic meters mine water every year, of which only about $25 \%$ is utilized. Land subsidence leads to serious soil erosion, while fewer than $20 \%$ of key state-owned coal mines have taken actions to tackle this problem. Three hundred million tons of gangue is produced each year, occupying 70 thousand hectares of land. About $70 \%$ soot, $90 \% \mathrm{SO}_{2}$, and $90 \%$ of $\mathrm{NO}_{x}$ come from coal-burning. The main reason for this is the high ratio of coal burned in small boilers or households. Only $53 \%$ of coal in China is used for power generation, lower than the world's average level of $65 \%$ and much lower than that of the U.S. (92\%) and Germany $(82 \%)$. 


\subsubsection{A period of strategic adjustment of coal industry}

The "golden decade" of China's coal industry came to an end in 2012, when the Bohai-Rim Steam-Coal Price Index dropped by over $50 \%$ compared to 2011. In 2014, profit of the industry fell by $45 \%$ year-on-year and over $70 \%$ companies registered losses. With the slowing of growth in demand, over-capacity, increasing homogeneous competition, and heavier burdens of environmental protection and emission reduction, the coal industry cannot continue to rely on expansion and investment for development. It has to transform and upgrade.

\subsubsection{Highlighted clean and efficient development and} utilization of coal

China has formed new strategies for revolutionizing energy production and consumption in the new period, emphasizing solutions to ecological and environmental damage caused by coal mining and consumption, and attaching great importance to the promotion of clean and efficient utilization of coal. The State Council $(2013,2014)$ has issued "Air Pollution Prevention and Control Action Plan" and "China Energy Development Strategy Action Plan: 2014-2020", to accelerate environment-friendly development of coal and its clean and efficient utilization.

\subsection{Characteristics of the coal-based integrated energy systems engineering of Shenhua}

\subsubsection{An overview of Shenhua Group}

As one of the 53 state-owned key enterprises directly supervised by the central government, Shenhua Group has, after twenty years of reform and innovation, established its coal-based integrated industrial chain of coal, electricity, railway, port, shipping, coal to liquids and chemicals, and it runs a complete supply chain of production, transport and trade, thus creating a unique Shenhua development mode. In 2014, the turnover of Shenhua reached 324.9 billion CNY with profit totaling 64 billion, ranking 165th among the Fortune Global 500 companies. By the end of 2014, Shenhua had 70 coal mines. Raw coal output and commercial coal sales led the world for many consecutive years while its mortality per million tons of raw coal output has been among the lowest in the world. In addition, with its 2,182 kilometers of railway, three ports with a combined annual capacity of nearly 300 million tons and a shipping fleet with 2.09 million deadweight capacity, Shenhua has built a great channel connecting coastal and riverine areas with "the second largest corridor" for the West-to-East Coal Transportation and some major ports as the hubs. The company also has power plants of $66.9 \mathrm{GW}$ total capacity with key performance indicators among the best in China, the first Direct Coal Liquefaction Demonstration Project with 1 million ton annual capacity and the first coal-toolefins demonstration project.

2.2.2 Complexities of coordinated management and control of Shenhua's multi-industrial systems engineering

Shenhua Group has a wide range of businesses; therefore, it requires sophisticated management and technologies. Compared to other ministry-turned-companies, Shenhua lacks a comprehensive network of research institutions, which resulted in weak R\&D foundation. The company is also faced with complexities and difficulties in coordinated management and control of the multi-industrial systems engineering.

2.2.3 Innovation as the key to coordinated management and control of Shenhua's multi-industrial systems engineering

Responding to the aforesaid difficulties, led by concept innovation, based on management innovation and supported by technological innovation, Shenhua has made great efforts to promote both technological innovation and management innovation. Adhering to its philosophy of "low-carbon development in a high-carbon industry, and green development and clean utilization through innovation," Shenhua has created a technological innovation model by combining both external and internal forces. Various world-leading technologies have been developed, such as technologies for coordinated development of coal resources and the environment, ultra-low emissions generation technologies and the environment-friendly development of coal-associated resources. Through management innovation, Shenhua has promoted the safe, green, efficient and smart development of coal, accelerated application of ultra-low emission technologies in its coal fleet, and pushed forward coal conversion and utilization and the codevelopment of coal and the associated resources. As a result, Shenhua has established three major coordination and control systems for the systems factors, resources and the environment and the extension of systems boundaries. In this way, optimal operation of the coal-based industrial chain has been achieved highlighting coordinated development of associated resources and coordinated development between resources and the environment.

\section{Innovation and practice in systems engineering management}

\subsection{Coordination among systems factors}

Coordinated development of Shenhua's coal-based industrial chain faces three challenges: first, resources allocation needs to be strengthened for coordinated management of the industrial chain; second, management mechanism of 
the industrial chain needs to be innovated to withstand market risks; third, operational command of different industries need to be coordinated so as to improve the synergy among production, transportation and sales. Coordinated development is an intrinsic requirement of the coal-based industrial chain, while clean and environment-friendly development is necessary for sustainability. Overall efficiency needs to be maximized to achieve sound economic returns, and safe and effective development is how a central SOE fulfills its political and social responsibilities. All these factors need to be considered to achieve synergized management and control of different industries.

\subsubsection{Management and technological innovation}

To achieve the coordinated development of the coal-based industrial chain while considering the constraints of nature, economy, the environment, society and technology, Shenhua has developed "the multi-industry coordinated management and control model" featuring differentiated management, professional control, shared service resources and standardized evaluations. By solving problems with regard to the management and control of development strategy, the integration of production, transportation and trade, the production chain and risks of the industrial cluster, Shenhua has maximized profit of the industrial chain with minimum operational cost, made the most out of its capital and best fulfilled its social responsibilities, improving Shenhua's capability to create values and fulfil its social responsibilities.

"The multi-industry coordinated management and control model" is a management and planning model based on the production and operation information at the core of Shenhua's production, transportation and trade network to optimize coal distribution and transportation against certain indicators. The fundamental principles of this model are:

(1) Create variables for optimized decision-making based on the network of the production, transportation and trade, coal mix and client groups;

(2) Establish optimization objectives based on requirements of the production and operation indicators of the coal distribution and transportation;

(3) Set up constraints based on the production and operation characteristics, demands and capabilities of the core businesses;

(4) Work out optimal solution to the model so as to get an improved allocation and transportation plan on the basis of balanced production, transportation and trade.

Based on "the multi-industry coordinated management and control model", Shenhua has established a number of management and control platforms of multi-industry strategy, coordinated production, connection between transportation and marketing, and risks monitoring. As a result, Shenhua constantly improved its capacity to produce, transport and converse coal, and enhanced the balance between coal and other energy sources, which have bolstered the coordinated and sustainable multi-industrial development.

\subsubsection{Typical cases}

(1) Optimized coordinated management and control of integrated operation

Through the optimized coordinated management and control of integrated operation, Shenhua has integrated the resources at industrial, regional and national levels, and those of internal departments and its partners. By creating, extending and enriching its industrial chain, Shenhua has established a modern coal-based energy industrial system with combined logistics, information flow and capital flow. The company also reached the goal of increasing the turnover rate of its industrial chain. It only takes about 11 days to produce coal in Shendong Coal Mine and deliver it to clients in coastal areas of southeastern China, 5 days less than its competitors (saving two days in loading and three days in port storage). The industrial chain has consumed 180 million tons of Shenhua coal, or $36.3 \%$ of it production, greatly reducing market risks.

(2) Localization of mining equipment

Shenhua was the first to put forward the "client-oriented" research model of coal equipment and technologies. Innovative industry-university-research institute cooperation was promoted following the guideline of "importing, absorbing, integrating, redesigning and manufacturing". Major breakthroughs were made in developing domestic coal equipment, including "the complete technology package for $6.3 \mathrm{~m}$ fully mechanized coal face," "high pressure, large volume pump station and system for fully mechanized coal mining," "study on the design of $7 \mathrm{~m}$ and two-column shield-type hydraulic support" and "the complete technology and equipment package for $8.8 \mathrm{~m}$ intelligent fully mechanized coal mining". As a result, locally-produced equipment has been recognized as being of internationally advanced standards; this broke the monopoly of foreign coal equipment suppliers, saving over 9 billion CNY procurement cost for Shenhua while creating a domestic market worth over 20 billion CNY.

(3) Technological innovation model based on resources integration

To deal with the technical challenge of the coordinated multi-industrial development and a lack of comprehensive research institutions, Shenhua has developed an inclusive model of technological innovation integrating both external and internal resources. Internally, Shenhua has established a platform of indigenous innovation, which consists of National Institute of Clean-and-low-carbon Energy, Institute of Technology and hi-tech companies. Externally, it has built a platform of coordinated innovation based on the integration of external resources so that academic work- 
stations, coal strategic alliances, postdoctoral workstations, institutes, universities, domestic and foreign large-scale enterprises can cooperate to conduct research and development. All these have greatly strengthened Shenhua's innovation chain of basic research, technological $R \& D$ and commercialization of research results. In recent years, more than 100 domestic and foreign research institutes have taken part in over 200 Shenhua projects, making a series of breakthroughs. In 2014, technological innovation in Shenhua generated more than 14.5 billion $\mathrm{CNY}$ in direct revenue and one of its research results won the second prize of the National Science and Technology Progress Award.

\subsection{Coordination between resources and the environment}

A big challenge of the coal industry is to coordinate factors such as resources of the mines, the environment and technology to overcome the constraints of resources and the environment, so as to achieve the coordinated development of resources and the environment in large coal mines.

\subsubsection{Management and technological innovation}

Shenhua aims to achieve "eco-friendly development" and "ultra-low emission" and adheres to the principle of "maximizing resources recycling, minimizing environmental damages and maximizing the energy utilization rate." It has established a coordinated management and control system for resources and the environment and created key technological systems and demonstration projects including coordinated development of mines with annual production of over 10 million tons and the environment, coordinated management and control between coal development and the surface ecological restoration, and technologies such as coal-fired generator units with ultralow emission and carbon capture, storage and utilization. In this way, Shenhua has systemically improved the balance between coal development and the environment.

\subsubsection{Typical cases}

(1) Coordinated management and control of coal mining and surface ecological restoration

Shenhua has developed technological systems to reduce damages caused by ultra-large workface development, to optimize the plant species and to restore ecology in ecologically fragile mines. Two hundred and forty four square kilometers of Shendong Coal Mine was treated, 1.3 times the areas affected by mining activities. Ninety-six percent of the land within the development range has been treated. Soil erosion was treated at a rate of $94.1 \%$ with a soil erosion modulus of 1.5. Vegetation coverage increased from $3 \%-11 \%$ at the beginning of the development to $78 \%$ in 2014 . We have successfully created a stable ecological environment, making Shenhua Group the only mining enterprise winning the China Environmental Protection Award.

(2) Coordinated development of mines with annual production of over 10 million tons and the environment

We have set up technological systems such as ultra-large workface development, methods and models to assess coordination, equipment deployment among mines, coal quality control and scientific allocation of water resources in coal mines. As a result, coal development has been made more intensive. Mines (open-cast) with annual production of over 10 million tons are at the core of Shenhua's coal production, and mining has become safer and more efficient. The safety indicator in Shenhua's mines has been one of the best around the world for four consecutive years. The coordination ratio of Shendong Coal Mine rose from $72 \%$ in 2005 to $91 \%$ in 2014 . Thanks to this outstanding achievement, Shendong won the second prize of National Science and Technology Progress Award.

(3) Coal-fired generator units with ultra-low emissions

Multiple pollutant removal technologies are used to remove soot, $\mathrm{SO}_{2}$, and $\mathrm{NO}_{x}$ from the flue gas of boilers so as to bring down emissions of all coal units to the standards of natural gas generation. This is the main feature of the "ultra-low emission" technology. On June 25th, 2014, China's first coal-fired generator unit with "ultra-low emission"-No. 4 350MW coal-fired unit went into operation in Shenhua Guohua Zhoushan Power Plant. According to field sampling, the soot, $\mathrm{SO}_{2}$, and $\mathrm{NO}_{x}$ concentration and other technical indicators were all lower than the emission limits of gas generators. Shenhua now possesses 20 such generator units, accounting for $1 / 3$ of the national total. The cost markup per $\mathrm{kWh}$ is kept below 0.02 $\mathrm{CNY}$.

(4) CCS (carbon capture and storage)

Shenhua invested 300 million CNY in Ordos of Inner Mongolia to initiate the 300,000-ton CCS demonstration project. This is the world's first CCS demonstration project injecting high concentration $\mathrm{CO}_{2}$ from the coal-to-liquids project into saline formations. In the project, Shenhua has developed key technologies in ultra-low permeability reservoir for large scale CCS in saline formations and established a systemic supervision and assessment system including ground monitoring, underground safety monitoring and diffusion and migration monitoring. So far, we have captured and stored more than 300,000 tons of $\mathrm{CO}_{2}$, improving China's voice in international climate negotiations.

\subsection{System boundary expansion coordination}

We have applied resource system boundary expansion theories, explored new ways to develop associated resources of coal and developed key technology in the coordinated development of associated resources through integrated innovation. 


\subsubsection{Innovation in management and technology}

Since 2014, Shenhua has developed "acid-base method", "water-acid method" and "one-step acid dissolution method" to extract alumina in fly ash, and Shenhua has also developed the technique of extracting gallium and silicon. We have completed the industrial test of producing 4,000 tons of alumina annually from the fly ash of circulating fluidized bed through "one-step acid dissolution method," and thus reached international levels in comprehensive utilization of fly ash.

Shenhua has made entry into the shale gas sector its major strategy to achieve green development. Shenhua carries out independent development at home and commercialized joint development abroad with regard to shale gas. Shenhua focuses on the combination of pilot projects and overall progress, and works with domestic and international partners to explore core technologies. At the same time, Shenhua vigorously pushes forward the joint development of coal and CBM through a combination of mining, advancing and gas drainage.

\subsubsection{Typical cases}

(1) Extracting alumina and gallium from fly ash

After more than ten years of coordinated innovation among industries, universities and research institutes, Shenhua has developed the "one-step acid dissolution method," the key technology to extract alumina. This new technology overcomes key engineering difficulties such as preventing equipment corrosion and dealing with acid gas, and it produces 4,000 tons of first grade alumina and 360 kilograms of $4 \mathrm{~N}$ gallium. With fewer processes, lower costs, this environment-friendly technology was the first of its kind in the world. In 2014, a 4,000 ton/year pilot plant was launched, producing $99.35 \%$ pure alumina that is superior to first grade alumina (98.6\%) and $99.99 \%$ pure gallium. Shenhua has gained 46 authorized patents and set up 4 corporate standards with this technology. Our circular economy demonstration project "coal-electricity-fly ashalumina" with planned investment of 140 billion CNY has been listed as one of the first demonstration bases for the comprehensive utilization of resources by the Ministry of Land and Resources and the Ministry of Finance.

(2) Development of unconventional natural gas from associated resources

Guided by the plan of exploring oil and gas in Baojing of Hunan Province featuring "overall design, step-by-step implementation, steady progress and risk avoidance," Shenhua carried out geological surveys, geophysical explorations, drilling and tests. Four parameter wells and one preliminary prospecting well were fractured for gas testing and succeeded in ignition. Progress has been made in Shenhua's shale gas development in Pennsylvania of the
U.S. with 29 shale gas wells drilled and five already in production.

Shenhua introduces advanced technologies from home and abroad to improve gas extraction and utilization and curb gas accidents. So far, 12 high gas and outburst mines have been equipped with gas extraction and utilization system. Gas extracted per year reaches 208 million cubic meters, accounting for more than $60 \%$ of the total. Gas utilized per year stands at $74 \times 10^{6} \mathrm{~m}^{3}$ with installed powergenerating capacity of 41.4 megawatt and an annual generation of $60.456 \times 10^{6} \mathrm{kWh}$.

\section{Conclusions}

Through establishing models and control platforms for coal-based comprehensive industrial development, coordinated development concept of coal and environment and management model, new model and engineering technology system of comprehensive utilization of associated resources, Shenhua has achieved coordination between internal factors of the energy system, in system boundary expansion and between its system and the environment.

Faced with the global trend of green energy and the requirements of development in a scientific way proposed by China, Shenhua is moving to transform itself from a coal producer to a clean energy supplier. Shenhua will develop new and renewable energy technologies including energy storage, hydrogen production through renewable resources, on-grid coordination between power produced from new energies and coal to realize full synergy of coal and its associated resources.

Shenhua's vision is to become a world-class clean energy supplier that has advanced technology and management, focuses on creating values and is driven by innovation. Shenhua will push forward the coal revolution and improve its core competitiveness, enrich and complete its integrated model through technological and management innovation, take on more responsibilities and obligations and supply cleaner energy to the world.

\section{References}

The Chinese Academy of Engineering. (2014). Research on China's clean, efficient and sustainable exploration and utilization of coal. Unpublished research report. The Chinese Academy of Engineering, Beijing, China

The State Council. (2013). Air pollution prevention and control action plan. The State Council Issues, No. 37. Retrieved from http://www. gov.cn/zhengce/content/2013-09/13/content_4561.htm

The State Council. (2014). China energy development strategy action plan: 2014-2020. The General Office of the State Council Issues, No. 31. Retrieved from http://news.xinhuanet.com/2014-11/19/ c_1113313588.htm 